مقاله يزوهشى

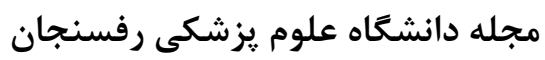

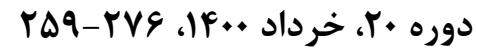

إيدميولوزى جغر افيايى خود كشى (كامل و اقدام) در شهر ستانهاى تحت يوشش دان دانشكاه علوم

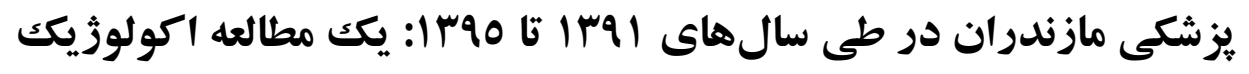

سعيد بيشبين'، رضا وزيرىنزاد'، يروين خليلى'، حسن احمدىنياء، محسن اعر ابى، عبدالكريم احمدى'، محسن رضائيان

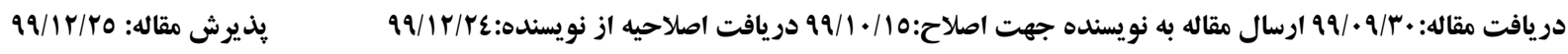
جكيده زمينه و هدف: خودكشى يكى از بزركترين مشكلات يزشكى و اجتماعى جهان است. مطالعه حاضر با هدف تعيين

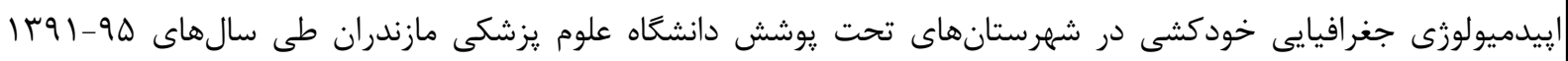
انجام شده است.

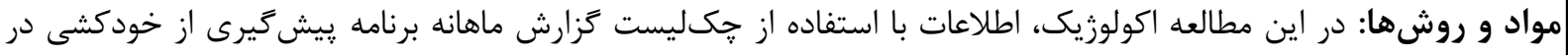

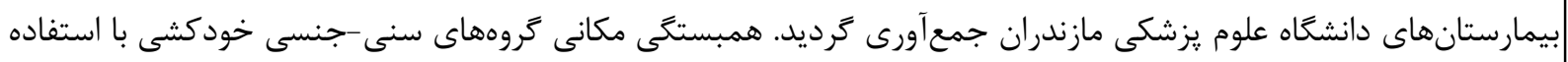

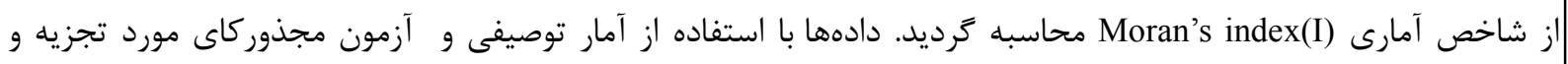
تحليل قرار ترفتند.

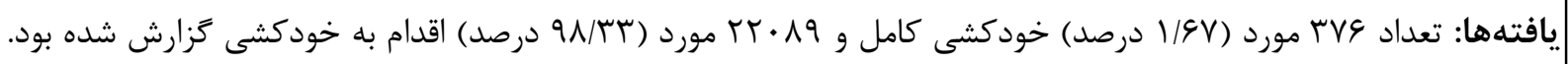

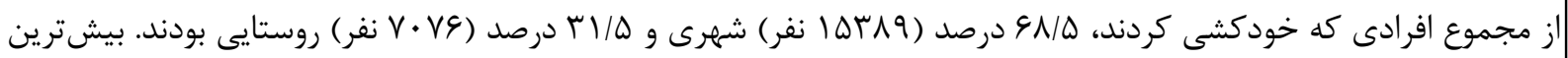

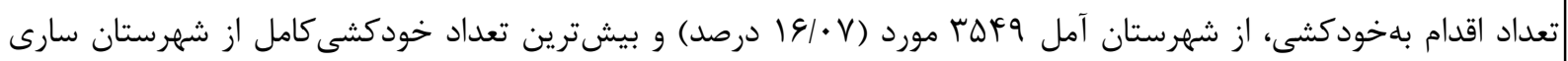

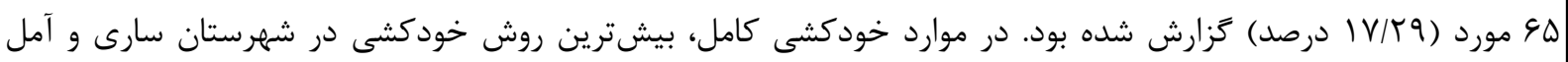

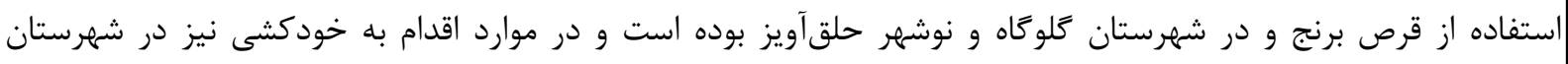

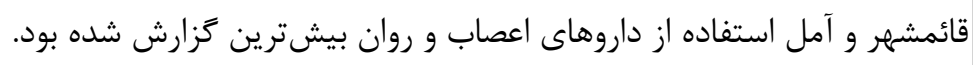

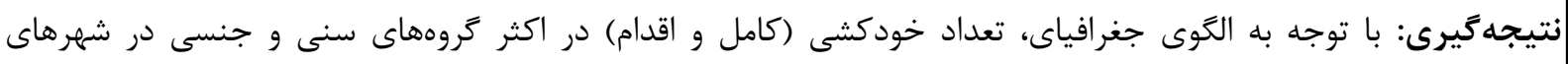

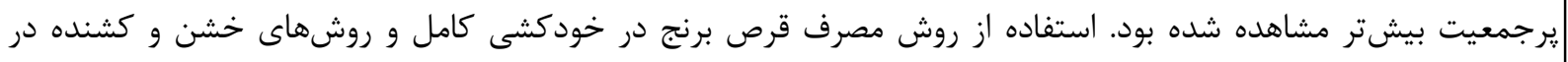
إبرخى از مناطق استان بالا بود.

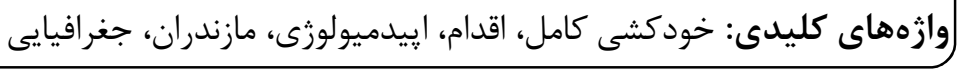

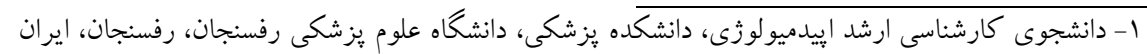

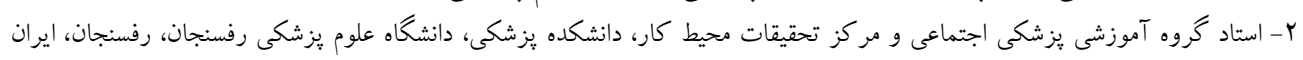

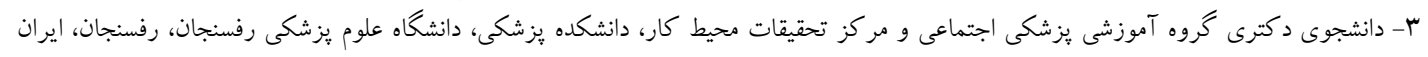

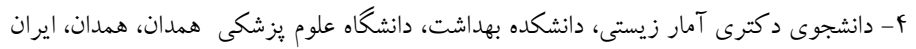

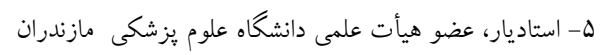

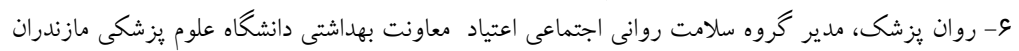

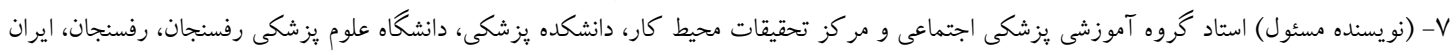

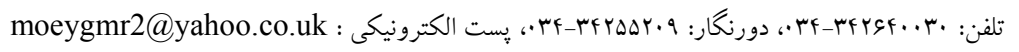


سراسر جهان از بين افرادى كه اقدام به خودكشى كردند

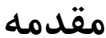

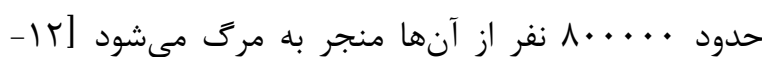

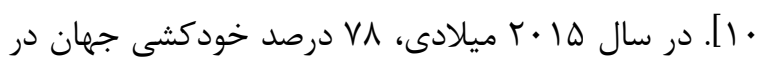
كشورهايى با درآمد كم و متوسط ززارش شده بود [.1]. خودكشى يكى از دليل اصلى مرگ جوانان در سراسر جهان مىباشد و در همه كشورهاى جهان همانند استراليا و آمريكا

$$
\text { رو به افزايش مىباشد [سر]. }
$$

يافتههاى حاصل از يزوهشها نشان داده است كه بيشترين گَزارش آمار خودكشى در جهان مربوط به كشورهاى

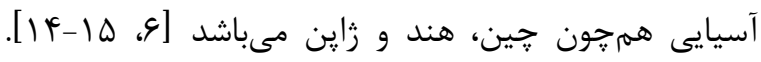
فراوانى خودكشى در كشورهاى مختلف، متفاوت مىباشد به طورى كه بيشترين گزارش از كشورهاى اسكانديناوى، آلمان، اروياى شرقى تا استراليا مىباشد و كمترين گزارش از اسپانيا، ايتاليا، ايرلند، هلند، مصر، فنلاند، مجارستان و كـشورهاى اسـلامى كه درصد يايينى را به خود اختصاص

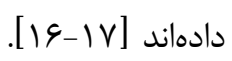

در ايران هر ساله درحدود f هزارخودكشى منجر به مرى اتفاق مىافتد كه بيشترين خودكشى منجر به مرى در استانهاى ايلام، تهران، فارس و كرمانشاه و كمترين موارد مرگ ناشى از خودكشى در استانهاى خراسان جنوبى، كهكيلويه و بويراحمد، يزد و كرمان گزارش گرديد [9 (111]]. ميزان مرك ناشى از خودكشى در ايران Y/V در صد هزار نفر در سال ها • r كزارش شده بود [•r]. با توجه به يافتههاى Rostami و همكارانش شهرستانهاى كرمانشاه، اسلامآباد غرب، دالاهو، كيلانغرب و كنغاور در
خودكشى اقدامى آكاهانه و ارادى كه در طى آن فرد با انجـام اقـداماتى مر خبــار بــه دسـت خويش زندكيش را پايان مىبخشد [1-1]. خودكشى يك مشكل جدى بهداشت عمومى در سراسر جهان به شمار مى آيد [צ-ب]. إيدميولوزى جغرافيايى را مىتوان به عنوان توصيف الكَوهاى فضايى از بيمارى و مرى و مير بيمارى تعريف كرد كه بخشى ازمطالعات إيدميولوزيك با ماهيت توصيفى دارد و يك تصوير جامعترى از يك مكان ايجاد مىكند [V]]. متخصصان بهداشت عمومى و إيبدميولوزى در ارزيابى اتيولوزى بيمارىهاى بهداشتى به إيدميولوزى جغرافيايى نياز دارند [V]. متغيرهاى سن، جنس و ساير موارد از يك مكانى به مكانى ديگر متفاوت مىباشد و همرجنين ممكن است در خطر بيمارىها و احتمال ابتلاء به بيمارى يا مرى تأثير كذار باشد [V]]. با توجه به افزايش رفتارهاى مربوط به خودكشى در سالهاى اخير در ايران، شناسايى و بررسى الكوهاى جغرافيايى آن مىتواند به پيش

$$
\text { مشكل بهداشتى كمك كند [1]. }
$$
نتايج مطالعهاى در طى سالع .. r از كشور آمريكا نشان داده بود كه خودكشى كامل و اقدام به آن تا حدودى الكَى جغرافيايى متفاوت داشتند و همجنين تراكم جمعيت در ميزان خودكشى مرتبط مىباشد [9]. براساس ززارش سازمان بهداشت جهانى خودكشى دومين عامل مرى و مير در گروه سنى ها تا وج ساله محسوب مىشود و سالانه در 
خودكشى متأثر از عوامل فرهنكى، منطقهاى و جغرافيايى

مىباشد، همرجنين در استان مازندران مطالعه إيدميولوزى جغرافيايى خودكشى مستند منتشر شدهاى صورت نكَرفته، ضرورى است تحقيقات لازم در اين زمينه انجام گيرد. لذا هدف از اين مطالعه تعيين إيدميولوزى جغرافيايى خودكشى كامل و اقدام به خودكشى در شهرستانهاى تحت يوشش دانشخاه علوم يزشكى مازندران در طى سالهاى |ج"ا تا ه9ץ إ مىباشد تا بتوان تصويرى بهترى از وضعيت موجود جهت ارائه دهندگان خدمات يِش گيرى از خودكشى ترسيم نمايد.

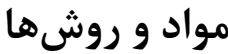

استان مازندران شامل I ش شهرستان با جمعيت  شمالى كشور واقع شده است، ·· شهرستان استان مازندران با جمعيت TVYAVDF تحت يوشش دانشكاه علوم يزشكى مازندران مىباشد [Vr-عץ]]. مطالعه اكولوزيك حاضر بر روى r شهرستان تحت :وشش دانشعاه انجام شده بود و كليه افرادى كه در بازه زمانى ابتداى سال |qجا تا پايان سال ه9 1ا خودكشى (كامل و اقدام به خودكشى) كرده بودند و به واحدهاى بهداشتى و درمانى شهرستانهاى تحت يوشش دانشگاه علوم يزشكى مازندران (مراكز بهداشتى درمانى و اورزانس بيمارستان) مراجعه كرده بودند و جى ليست كامل شده بود، مورد بررسى قرار گرفتند. جهت مقايسه با مطالعات
استان كرمانشاه بيشترين خودكشى (كامل- اقدام) گزارش شده بود [ [T]]. يافتههاى Taziki و همكارانش در رابطه همه كَيرى شناسى خودكشى در استان كلستان بيشترين ميزان خودكشى در قوميت فارس بومى، تركمن و سيستانى كزارش كرديد [Tr] يافتهاى يزوهش Haghparast-Bidgoli نشان مىدهد كه تغييرات جغرافيايى و زمانى در ميزان مرى و مير خودكشى با وضعيت متفاوت اجتماعى در استانها و با كذشت زمان ارتباط نزديكى دارند [بr]. همرجنين در مطالعه انجام شده در تايوان بين درجه حرارت هوا، رطوبت، تابش نور خورشيد، فشار جوى و فصل و سال با خودكشى ارتباط معنى دارى مشاهده شد [YF]. همرجنين با توجه به يافتههاى Daliri فصل) و عوامل جغرافيايى و جوى مىتوانند بر ميزان بروز خودكشى (كامل- اقدام) مؤثر باشند [هr]. مطالعات نشان دادهاند كه عوامل دموكرافيك همجون سن، جنس، عوامل فرهنكى، اجتماعى و اقتصادى [צr-9 سلامت جسمى، اعتياد به الكل، مواد مخدر [اب-•ץ] بيمارىهاى روانى و افسردگى، مشكلات مالى و قانونى و از دست دادن يكى از نزديكان [سז-rr]] حتى شرايط اقليمى، جغرافيايى، سابقه خانوادگى خودكشى، دين و مذهب [^، هر كدام به نحوى در بروز خودكشى مؤثر هستند. تفاوت جنسيتى در روشهاى خودكشى و كَناكونى الكوهاى خودكشى در مناطق جغرافيايى دنيا تفاوت دارد [هـ]. 
آمارى Moran’s index(I) استفاده گرديد. دامنه اين شاخص آمارى، مقاديرى بين 1- (نشان دهنده يراكندگى كامل) تا 1+ (همبستخى كامل بين مناطق) متغير مىباشد. در آزمون فرضيات، مقدار P كمتر از هـ/• به عنوان سطح معنىدارى در نظر گرفته شد. براى ترسيم نقشه دادههاى خودكشى (كامل و اقدام) از نرمافزار Arc GIS نسخه · ا استفاده شد. در اين مطالعه يك طرح رنغ از سبز به قرمز در نقشهها استفاده شد كه براى نشان دادن شهرستانهايى كه بالاترين بروز ه ساله را داشته رنت قرمز و شهرستانهايى كه كمترين بروز را داشته رنخ سبز تيره انتخاب گرديد. شهرستان بابل تحت يوشش دانشكاه علوم يزشكى مازندران نمىباشد و در نقشه به رنگ سفيد مشخص شده است. نتايج

در طى سالهاى |qج| تا هوج| با توجه به معيار ورود به مطالعه تعداد TYFA نفر دست به خودكشى (كامل و اقدام) زده بودند كه جهت درمان به واحدهاى بهداشتى و درمانى تحت يوشش دانشخاه علوم يزشكى مازندران آورده

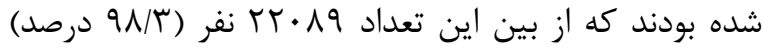
اقدام به خودكشى و YV نفر (1/9V درصد) خودكشى كامل كرده بودند. نسبت اقدام به خودكشى به خودكشى كامل برابر QN/VD مىباشد و نسبت اقدام به خودكشى به خودكشى كامل در شهرستانهاى نور، سارى، جويبار، نوشهر، جالوس، رامسر، ميان رود و كلو گاه كمتر از • له مىباشد كه در اين شهرستانها خطر خودكشى بيشتر است. ميانگين و
ديگر در ساير نقاط كشور ميزان بروز خودكشى به صورت تجمعى ل ساله محاسبه شد. دادههاى جمعيت شناختى در جكليست گزارش ماهانه برنامه بِيش جنس، محل سكونت، وضعيت تأهل، شغل، تحصيلات، سابقه بيمارى جسمى، سابقه بيمارى روانى، سابقه اقدام، سابقه اعتياد، زمان خودكشى، دليل و روش خودكشى مىباشد، مورد بررسى و مطالعه قرار گرفت. اطلاعات كليه افرادى كه خودكشى كرده و ساكن ساير استانها و يا ساكن شهرستان بابل كه تحت يوشش دانشعاه علوم يزشكى مازندران نبودند

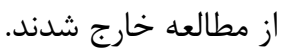
جكليست گزارش ماهانه به صورت مراجعه حضورى جمعآورى شد. براى جلوكيرى از كم شمارشى يا جاماندن دادهها و همجنين جهت افزايش دقت در جمعآورى دادهها، بايكانى آمارى كارشناسان بهداشت روان و حراست مراكز بهداشتى و درمانى و بيمارستانهاى تمام شهرستانهاى تحت يوشش دانشخاه علوم يزشكى مازندران كنترل به عمل آمد. نام، مشخصات و آدرس افراد كاملاً محرمانه مىباشد. اين يزوهش در كميته اخلاق دانشكاه علوم يزشكى رفسنجان با كد اخلاق IR.RUMS.REC.1397.064 تصويب گرديد. پس از كنترل اوليه از نظر صحت و كامل بودن اطلاعات، دادهها كدَذارى و سيس وارد نرم افزار آمارى SPSS شد و مورد تجزيه و تحليل قرار گرفتند. نسبت اقدام به خودكشى به خودكشى كامل محاسبه شد. جهت همبستگى مكانى كَروهاى سنى -جنسى خودكشى (كامل و اقدام) از شاخص 
در طى سالهاى مورد بررسى، بيشترين ميزان استاندارد شده خودكشى كامل در .1 هزار جمعيت مردان از شهرستانهاى كلوكاه، جويبار، نور، نوشهر و خالوس بود و كم ترين آن متعلق به شهرستان سيمرغ و سوادكوه (صفر) بود. در جنس زنان بيشترين ميزان استاندارد شده خودكشى كامل در ․ هزار جمعيت از شهرستان كلاردشت، فريدونكنار، جويبار و نوشهر بود و كمترين آن متعلق به شهرستان سيمرغ و عباسآباد (صفر) و بهشهر بود. با توجه به جدول ז، تعداد افرادى كه خودكشى كامل كردند در شهر الr نفر (Q9 درصد) و در روستا Dها نفر (أl درصد) و همرجنين اقدام به خودكشى در شهر $191 \mid$

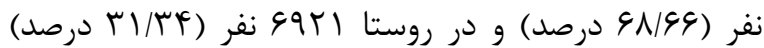
كزارش شده بود. كل افرادى كه در شهر خودكشى (كامل و اقدام) كردند نفر (Q/اس درصد) كزارش شده بود. بيشترين بروز ه ساله خودكشى كامل از شهرستان سارى و آمل و همجنين كم ترين آن متعلق به شهرستان سيمرغ (صفر)، عباسآباد، كلاردشت، مياندرود و سوادكوه گزارش شده بود و همجنين بيشترين بروز ه ساله اقدام به خودكشى از شهرستان قائمشهر و آمل و همجرنين كمترين آن متعلق به شهرستان سيمرغ و مياندرود كَارش شده بود. در شهرهاى آمل و قائمشهر و سارى خودكشى (كامل و اقدام) در شهر بيشتر از روستا اتفاق افتاده بود.
انحراف معيار سنى تمام موارد خودكشى (كامل و اقدام) برابر

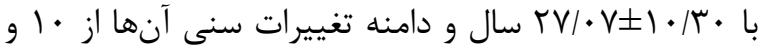

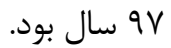
با توجه به جدول ا، بيشترين تعداد ززارش اقدام به

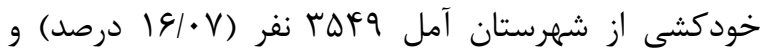

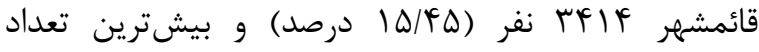
خودكشى كامل از شهرستان سارى له نفر (V/T9 ا درصد) و

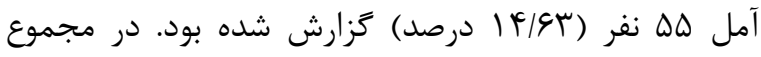
خودكشىهاى انجام شده از شهرستان آمل و قائمشهر و سارى بيشتر از ساير شهرستانهاى تحت يوشش دانشعاه خودكشى كزارش گرديد. تعداد خودكشى در ميان زنها از

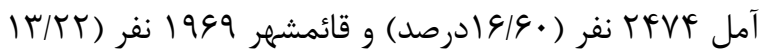
درصد) و در ميان مردها از قائمشهر IF/DQ ا نفر

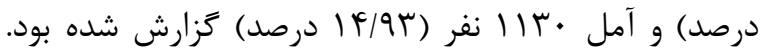
روش محاسبه ميزان در اين جدول سطرى و ميزان خودكشى در هر صد هزار نفر به دست آمده است و تعداد افرادى كه خودكشى كرده بودند به تفكيك هر شهر بر جمعيت آن شهرستان تقسيم شده است كه اين روش محاسبه مىتواند نشان دهد كه در جه شهرستانى بيشترين ميزان اقدام به خودكشى و خودكشى كامل كَارش شده است. ميزان بروز ه ساله خودكشى كامل IT/VA و اقدام به خود كشى 19/49 و كل خودكشى ع هزار نفر كزارش شده بود. بيشترين ميزان خودكشى كامل، از شهرستانهاى جويبار و نوشهر و اقدام به خودكشى از شهرستان فريدونكنار، قائمشهر و كلاردشت گزارش شده بود. 
F Y إييدميولوزى جغرافيايى خود كثى (كامل و اقدام) در شهرستانهاى ....

\begin{tabular}{|c|c|c|c|c|c|c|c|c|c|c|c|c|}
\hline \multirow[b]{2}{*}{ 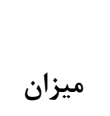 } & \multicolumn{2}{|c|}{ مجموع (n= (nF\&\&) } & \multirow[b]{2}{*}{ تعداد } & \multicolumn{4}{|c|}{ اقدام به خودكشى (n) (n) } & \multicolumn{4}{|c|}{ خودكشى كامل (n= rV9) } & \multirow{2}{*}{ شهر } \\
\hline & جمعيت & درصد & & 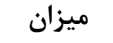 & جمعيت & درصد & 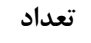 & ميزان & جمعيت & درصد & تعداد & \\
\hline $91 \Delta / 4 \Delta$ & IIrqur & r/q4 & $1 \cdot \mathrm{kr}$ & 19T/DT & IIrqur & $\varphi|9|$ & $1 \cdot 11$ & rI/qr & IIrqur & 9190 & ra & 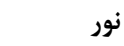 \\
\hline$\Lambda \Delta F / F G$ & FTIVAF & $|9| \cdot \varphi^{k}$ & 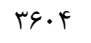 & $\Lambda F I / F r$ & FTIVAF & $191 \cdot V$ & rofq & $1 r / \cdot F$ & FYIVAF & $\mid f / g r$ & $\Delta \Delta$ & آمل \\
\hline$V r \cdot / \mu \cdot$ & $q f \| l f$ & $r / \cdot r$ & $9 \vee \wedge$ & $V \cdot \Lambda / V I$ & $q f \| l f$ & $r / \cdot r$ & $99 \mathrm{~V}$ & $11 / 99$ & $94 \| 1 f$ & r/9 & 11 & محمود آباد \\
\hline १५१/१९ & $M I V \cdot V$ & $\Delta / \Delta)$ & Irr人 & qrr/^q & $M I V \cdot V$ & $\Delta / \Delta V$ & $1 r r$. & $\varphi / \cdot V$ & $I r I V \cdot V$ & $r / 1 r$ & $\wedge$ & بابلسر \\
\hline $11 \cdot \hat{\kappa} / \mathrm{A}$. & rIr.qr & $\mid \Delta / r F$ & TFFA & $1.94 / 91$ & rIT.9r & $\mid Q / f \Delta$ & mfIf & $1 \cdot 119$ & rIT.qr & $9 / \cdot 4$ & re & قائمشهر \\
\hline$r \& N / r$. & fqfrul & $1 \cdot \pi \cdot$ & TrIf & $\uparrow \Delta \Delta / \cdot \Delta$ & FAFTHI & $1 \cdot 111$ & TrFq & $1 \pi / 1 \theta$ & Fqferl & $1 V / r q$ & $9 \Delta$ & سارى \\
\hline $1 \cdots / 09$ & VYFAT & T/VG & Gr. & $V V F / V V$ & VVFFT & T/VT & $4 .$. & TQ/AT & VVFFT & $\Delta / r T$ & $r$. & جويبار \\
\hline $9 \vee N /{ }^{2}$ & ||$\wedge r G \mid$ & $\Delta / 1 \Delta$ & $11 \Delta 1$ & $৭ ९ \triangleright / ८ 9$ & ||$\wedge r q \mid$ & $\Delta / I V$ & $11 \mathrm{kT}$ & $I T / 9 V$ & ||$|\wedge r|$ & $r / 99$ & 10 & نكا \\
\hline NIV/RT & |rAKT| & $F / 9 V$ & $1 \cdot \psi_{\Lambda}$ & Vqr/qF & |YATY| & $f|9|$ & $1 \cdot 11$ & rr/rq & |rAYTI & V/91 & $r$. & نوشهر \\
\hline$\Lambda \Lambda \Delta / \Delta)$ & IIGDFT & $r / \Delta q$ & $1 \cdot r T$ & NGY/9T & IIGDFT & $F / D G$ & $1 \cdots 1$ & $r \cdot 109$ & IIGQFT & $9 / \pi \Lambda$ & TF & جالوس \\
\hline ITVK/TY & rrGYA & $1 / 4 \Delta$ & TTD & $|r \Delta V / F|$ & rrgYA & $1 / 4 \Delta$ & TrI & $19 / 91$ & rrGFA & $1 / .9$ & f & كلاردشت \\
\hline $1 \cdot 11 / 99$ & IGKGAK & $\mathrm{V} / \mathrm{A \Lambda}$ & $|V V|$ & 1.99199 & IGKGAT & $v / q$. & IVES & $I Q / T V$ & IGTGNK & 9190 & $r \Delta$ & تنكابن \\
\hline$\Delta F \mid / \Delta r$ & VHSVQ & T/VG & Gr. & ^rr/Aq & VHSVD & T/VQ & $4 \cdot V$ & $\mid V / 90$ & $V M G V \Delta$ & $r / 4 \varphi$ & Ir & رامسر \\
\hline 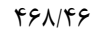 & $\Delta \omega \cdot V r$ & $1 / 10$ & $r \Delta \Lambda$ & $|99| / r \mid$ & $\Delta \Delta \cdot V r$ & $1 / 10$ & TQF & $V / T G$ & $\Delta \Delta \cdot V r$ & $1 / .9$ & r & سوادكوه \\
\hline$V I \cdot / \mu F$ & $\Delta \Delta r T \Delta$ & $1 / V \Delta$ & r & $V \cdot 1 / \pi 1$ & $\Delta \Delta r T \Delta$ & $1 / V 9$ & rM & $9 / \cdot F$ & $\Delta \Delta r T \Delta$ & I/r & $\Delta$ & عباس آباد \\
\hline $191 / \cdot V$ & rAVTq & . & $V F$ & $I N \cdot N F$ & rAVrq & . & $v \cdot$ & $1 \cdot \pi r$ & ravrq & $1 / .9$ & r & ميانرود \\
\hline$G \cdot r / A T$ & $\Delta \wedge r q r$ & $1 / \Delta V$ & TAT & $\Delta / \Lambda \mu q$ & $\Delta \wedge r q T$ & $1 / Q F$ & $r+1$ & IN/AF & DیrqT & r/9 & 11 & كَلوكاه \\
\hline$\Delta r q / r \Delta$ & $|\Lambda \cdot r|$ & $\cdot / f F$ & 99 & $\Delta F q / r q$ & $|\Lambda \cdot r|$ & $\cdot / 4 \Delta$ & 99 & $\cdot \cdot \cdot$ & $|\Lambda \cdot r|$ & $\cdot 1 \cdot$ & . & سيمرغ \\
\hline$|r \cdot 9 / r|$ & $q^{\mu} \cdot 19$ & $r / r q$ & VAT & $11 / N / \Delta 9$ & $9 \mu \cdot 19$ & T/rq & $V F q$ & $r \cdot \mid q r$ & $9 \mu \cdot 19$ & $r / 4 \varepsilon$ & Ir & فريدونكنار \\
\hline $9 \Delta \Gamma / \Gamma \Delta$ & $1 V \cdot V 94$ & $V / T \Delta$ & IGYA & $q F V / F q$ & $I V \cdot V \& \varphi$ & $V / T r$ & 1911 & $\Delta / \wedge \varphi$ & $1 V \cdot V G 4$ & $r / 99$ & 1. & بهشهر \\
\hline NTr/KG & TVTAVDF & & TrFED & $1 \cdot 9 / 4 q$ & TVTAVDF & $91 / \mu r$ & $r T \cdot \wedge q$ & $I T / V \Lambda$ & TVTAVDF & $1 / 9 V$ & rVG & مجموع \\
\hline
\end{tabular}




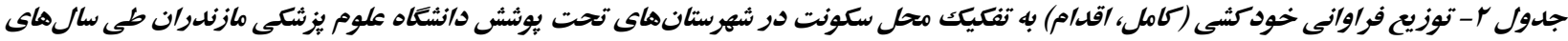

$1491-1490$

\begin{tabular}{|c|c|c|c|c|c|c|c|c|c|c|c|c|}
\hline \multicolumn{4}{|c|}{ مجموع (n= YYF\&D) } & \multicolumn{4}{|c|}{ اقدام به خودكشى (n= = (n) } & \multicolumn{4}{|c|}{ خودكشى كامل (n= rVq) } & \multirow{3}{*}{ شهر } \\
\hline \multicolumn{2}{|c|}{ روستايى } & \multicolumn{2}{|c|}{ شهرى } & \multicolumn{2}{|c|}{ ل } & \multicolumn{2}{|c|}{ شهرى } & \multicolumn{2}{|c|}{ روستايى } & \multicolumn{2}{|c|}{ شهرى } & \\
\hline درصد & تعداد & درصد & تعداد & درصد & تعداد & درصد & تعداد & درصد & تعداد & درصد & تعداد & \\
\hline$q q / q v$ & 019 & $\Delta \cdot / \Delta r$ & $\Delta T V$ & $\{q / \Delta 1$ & $a \cdot f$ & $0 \cdot / 49$ & DIf & is & ir & $\Delta T$ & ir & نور \\
\hline$r \cdot / \uparrow \Delta$ & $1 . .4$ & $\varepsilon 9 / \Delta \Delta$ & rrqu & re & 919 & st & rre. & r & iv & 99 & rı & آمل \\
\hline$+1 / 10$ & rvq & $\Delta N / \wedge \Delta$ & ५१९ & il & rVT & $\Delta 9$ & $r q \Delta$ & st & v & rq & r & محمود آباد \\
\hline$r / l$ & re & $9 \vee / \wedge 9$ & IrIT & r & ra & 91 & $I r \cdot \Delta$ & $\mid r / \Delta$ & 1 & $\Lambda V / \Delta$ & v & بابلسر \\
\hline $\mid q / T q$ & pqr & $\wedge \Delta / \vee$ & $r q \Delta \Delta$ & if & YAV & $\wedge$ & ratr & 11 & 4 & NT & rA & قائمشهر \\
\hline $19 / \pi \Lambda$ & rvq & NH/Gr & $194 \Delta$ & 19 & $r \Delta \Delta$ & Af & 1199 & $r v$ & re & s & il & سارى \\
\hline $94 / \pi q$ & rq & $r q|9|$ & TrV & q & rvq & $r v$ & TrI & $v$. & if & $r$. & 4 & جويبار \\
\hline$r q / \Lambda$. & $r \cdot r$ & $90 / 19$ & $v \Delta \Delta$ & ra & एव९ & 90 & $V F V$ & iv & v & Lr & $\wedge$ & نكا \\
\hline $\mid q 9 / 1)$ & QTT & $\Delta \cdot / 19$ & DrE & $4 q$ & $\Delta \cdot r$ & DI & 019 & $9 V$ & $r$. & rr & 1. & نوشهر \\
\hline rg/Tr & rVF & sr/VG & $9 \Delta \Lambda$ & is & rgV & $\Delta \Delta$ & $s+1$ & rq & v & 91 & IV & جالوس \\
\hline$V T / Q F$ & rrq & $r \& / 4 \&$ & $\wedge \varepsilon$ & $V Y / T I$ & rta & rq/Vq & $\wedge \varphi$ & $1 \cdots$ & r &.$/$ & . & كلاردشت \\
\hline$\Delta T / Q T$ & $१ \Delta \Delta$ & $|q \varepsilon| \cdot 1$ & 118 & $\Delta F$ & $94 \mathrm{r}$ & \&4 & $\Lambda \cdot r$ & $\psi_{\wedge}$ & Ir & $\Delta r$ & Ir & تنكابن \\
\hline$r r / q$. & $r \cdot r$ & $9 \mathrm{~V} / \cdot 9$ & pis & r & 199 & $q V$ & $r \cdot \wedge$ & r & $\Delta$ & ar & $\wedge$ & رامسر \\
\hline$r \Delta / \Delta \Lambda$ & 94 & VE/FT & 195 & ra & $q 4$ & $V \Delta$ & 19. & $\Delta$. & r & $\Delta$. & r & سوادكوه \\
\hline$\Delta \Delta / G T$ & 194 & $\Delta N / \Delta r$ & rr. & FT & 195 & $\Delta \Lambda$ & TrG & $r$. & 1 & $\wedge$. & r & عباس آباد \\
\hline HN/FG & ro & $G / / \Delta F$ & $\Delta \varphi$ & qr & r & $\Delta \varphi$ & rq & $1 \cdots$ & q & $\cdot /$ & . & ميانرود \\
\hline IT/Tr & re & $\Lambda \vee / V \vee$ & TFE & $r$. & 1.4 & v. & rrv & TG & r & $g 4$ & v & كلو كَاه \\
\hline$r \Delta$ & $i \Delta$ & $\Delta \Delta$ & $\Delta F$ & $i \Delta$ & $i \Delta$ & $\Delta \Delta$ & $\Delta F$ &.$/$ & . &.$/$ & . & سيمرغ \\
\hline rN/19 & rq1 & $91 / 11$ & in & rı & rAD & GT & rat & iq & 4 & $\Delta F$ & v & فريدونكنار \\
\hline$r \Delta / \Delta \gamma$ & $\Delta \vee q$ & $G F / F$ & $1 .+99$ & re & $\Delta V V$ & gf & $1 .+41$ & $r$. & $r$ & $\wedge$. & $\wedge$ & بهشهر \\
\hline$r 1 / 49$ & $v \cdot v q$ & $G N / D$. & lorAq & rז/וז & s9r1 & GN/GG & 10191 & il & $1 \Delta \Delta$ & $\Delta 9$ & MrI & كل \\
\hline
\end{tabular}

ميزان استاندارد شده اقدام به خودكشى در كل جمعيت متعلق به شهرستانهاى قائمشهر، تنكابن، كلاردشت و فريدونكنار و همرجنين كمترين ميزان استاندارد شده اقدام به خودكشى از شهرستان مياندرود در ․ هزار جمعيت به دست آمد.
با توجه به نقشه l ، بيشترين ميزان استاندارد شده خودكشى كامل در كل جمعيت متعلق بهشهرستانهاى حلوFاه و جويبار وكمترين ميزان از شهرستان سيمرغ و كلاردشت در . هزار جمعيت گزارش گرديد (شهرستان بابل تحت يوشش دانشگاه علوم يزشكى مازندران نيست و به رنگ سفيد نشان داده شد). با توجه به نقشه r ז، بيشترين 


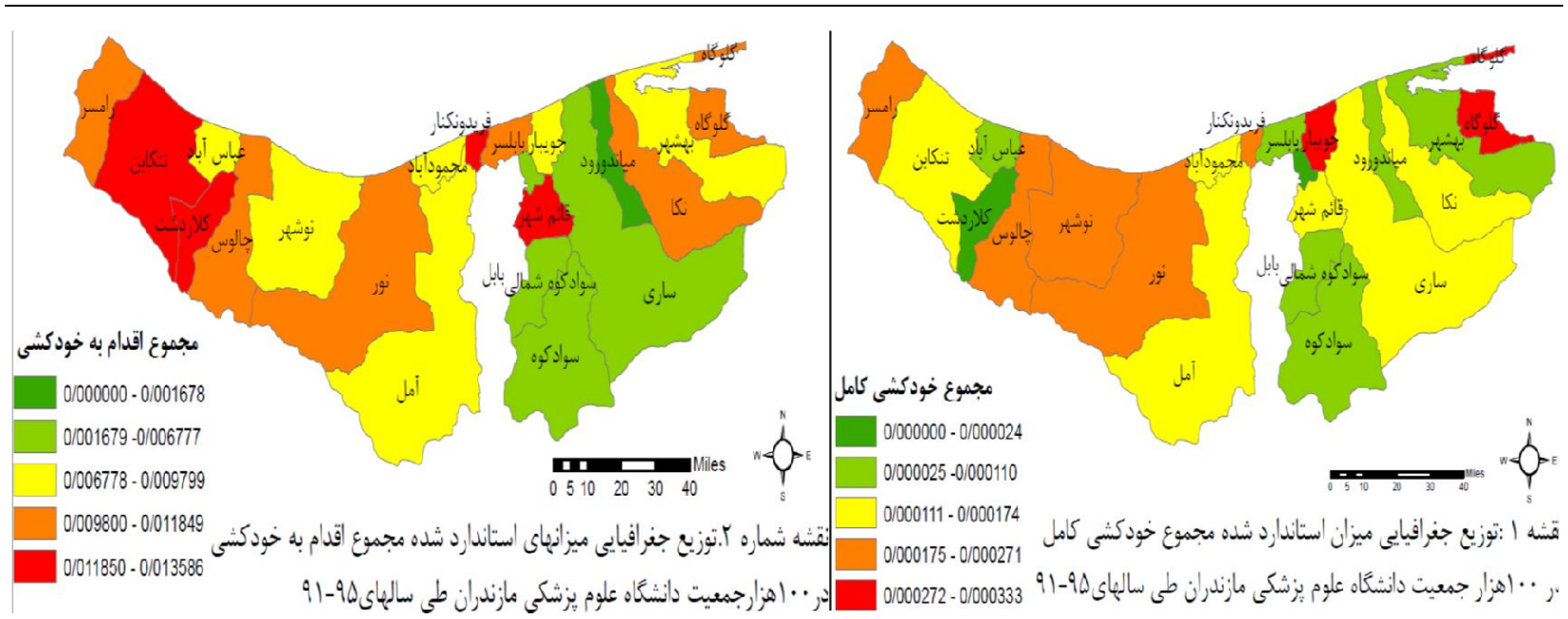

روش حلق آويز از شهرستان سيمرغ، عباسآباد (اين T شهر صفر)، سوادكوه، بابلسر، نور و مياندرود كزارش شده بود. در رابطه استفاده از روش خودسوزى از شهرستان سارى و نوشهر ززارش بيشترى شده بود و همجنين از شهرستانهاى سيمرغ، عباسآباد، سوادكوه، نكا، تنكابن، رامسر، جويبار، محمودآباد، فريدونكنار و قائمشهر در رابطه استفاده از روش خودسوزى در خودكشى كامل كزارشى نشده بود. با توجه به نقشه fا، توزيع جغرافيايى روش استفاده از قرص برنج در افرادى كه خودكشى كامل كرده بودند از شهرستان سارى و آمل بيشترين گزارش و هم جنين از شهرستانهاى سيمرغ، كلاردشت، كلوكاه (اين r شهر صفر)، بهشهر و مياندرود كمترين گَزارش ثبت شده بود. با توجه به نقشه ه، در رابطه استفاده از روش مصرف داروهاى اعصاب و روان در اقدام به خودكشى، از شهرستان قائمشهر و آمل بيشترين و كمترين آن متعلق به شهرستان

$$
\text { سيمرغ و مياندرود ززارش شده بود. }
$$

طبق نقشه سا، بيشترين بروز ه ساله كل خودكشى (كامل، اقدام) از شهرستانهاى قائمشهر و آمل و كمترين آن متعلق به شهرستان سيمرغ، عباسآباد، كلاردشت، مياندرود، سوادكوه و گلوكاه گزارش شده بود. قابل توجه است كه شهرستانهاى سارى و قائمشهر و آمل از شهرهايى با جمعيت و وسعت بيشترى هستند و هم:جنين داراى بيمارستانهاى مختلف و شهركهاى صنعتى مختلفى مى

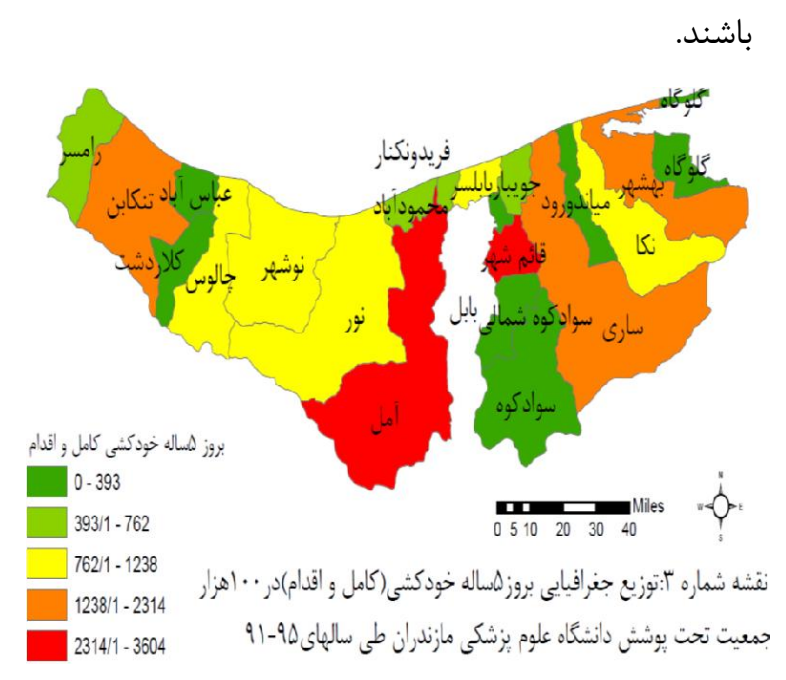

بيشترين روش حلقآويز در خودكشى كامل، متعلق به

شهرستان كلوكاه و نوشهر و همرجنين كمترين استفاده از 


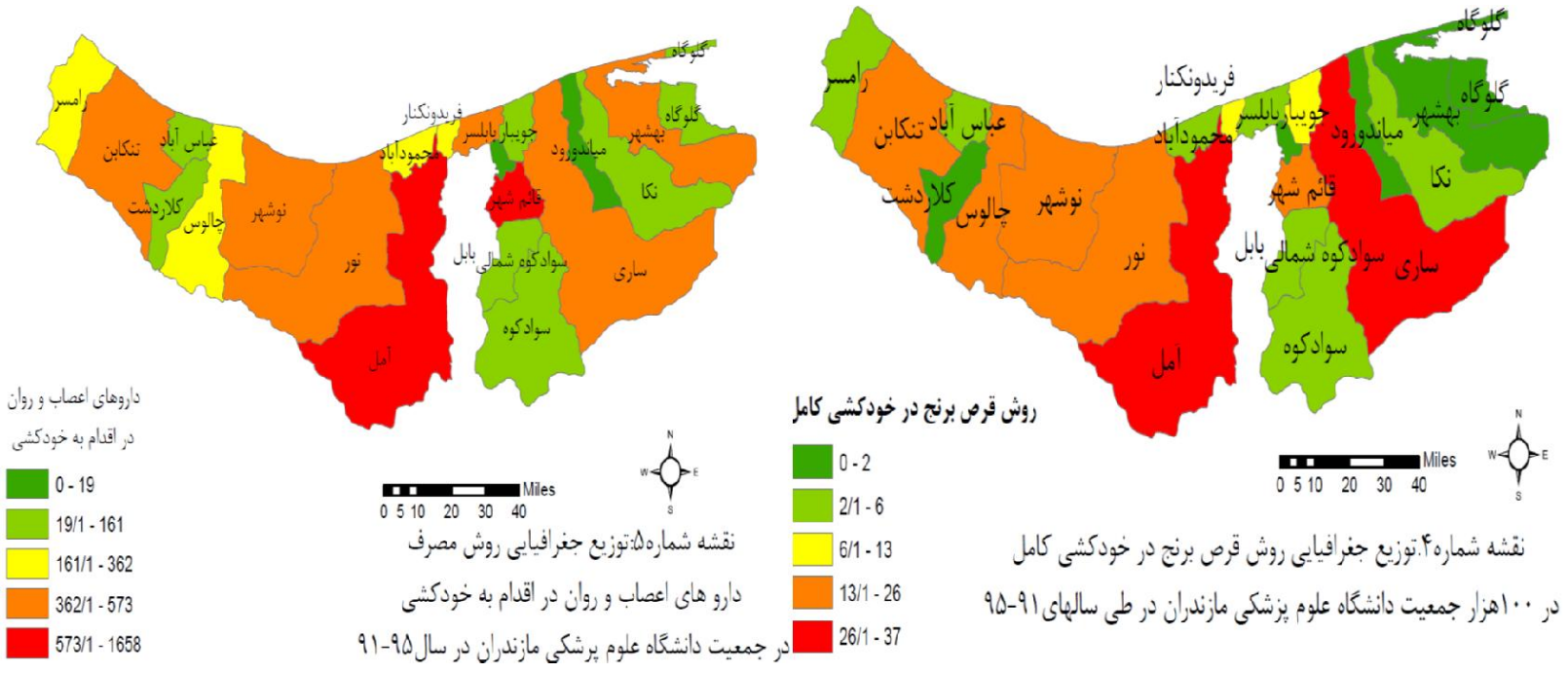

مياندرود ززارش شده بود. در رابطه استفاده از داروى ترامادول در اقدام به خودكشى از شهرستان قائمشهر و آمل بيشترين و كمترين آن متعلق به شهرستان سيمرغ، كلاردشت، كلو كاه و مياندرود ززارش شده بود.

Moran’s index (I) با توجه به جدول rا، شاخص آمارى در تمام گروه سنى مقدار P بيشتر از ه•• • مىباشد كه معنى دار نمىباشد و عدم همبستخى مكانى را نشان مىدهد و هيتج گَونه شواهدى از همبستخى فضايى مشاهده نكرديد و همجنين مقادير منفى نشان مىدهد كه الكَى مقادير در مكانهاى مجاور يراكندهتر است.
روش انجام خودكشى در افرادى كه اقدام به خودكشى كرده بودند در ․ هزار جمعيت شهرستانهاى تحت يوشش دانشخاه علوم يزشكى مازندران طى سالهاى ه9ب I| | ا نشان مىدهد كه بيشترين جمعيتى كه از روش قرص برنج استفاده كرده بودند، متعلق به شهرستان قائمشهر، سارى و آمل و همرجنين كمترين آن متعلق به شهرستان سيمرغ، كلاردشت، گلو مياندرود و نكا گزارش شده بود. بيشترين جمعيتى كه از روش مسموميت استفاده كرده بودند از شهرستان قائمشهر، آمل، سارى و تنكابن و كمترين آن متعلق به شهرستان سيمرغ، كلاردشت، عباسآباد و 
^عץ اييدميولوزى جغرافيايى خود كشى (كامل و اقدام) در شهرستانهاى ....

جلول با - بورسى شاخص Moran's index (I) خودكشى كامل و اقدام به خودكشى تجمعى بين كروهناى سنى-

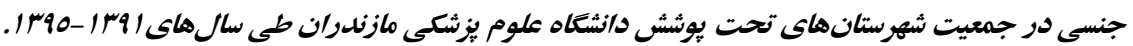

\begin{tabular}{|c|c|c|c|c|c|}
\hline \multicolumn{2}{|c|}{ اقدام به خودكشى } & \multicolumn{3}{|c|}{ خودكشى كامل } & \multirow{2}{*}{ كروه سنى (سال) } \\
\hline Pقدار P P P & Moran's index (I) & Pقدار P P P & Moran & (I) & \\
\hline$\cdot \mid \Delta \wedge \Lambda$ & $-\cdot / \cdot 19$ & • &.$- / .14$ & مرد & \multirow{2}{*}{$I V-\Delta$} \\
\hline$\cdot 1099$ & $-.1 \cdot 10$ & $\cdot / 411$ &.$- / 111$ & زن & \\
\hline$\cdot 190$. & $-.1 . \Delta k$ & - RQAF &.$- / 111$ & 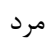 & \multirow{2}{*}{$r 9-11$} \\
\hline$\cdot / 1 \Delta \varphi$ & $\cdot 1 \cdot F \Delta$ & $\cdot / \Delta \vee q$ & $-\cdot \mid \cdot 11$ & زن & \\
\hline . MANV &.$- / . . p$ & . NGV &.$- / \cdot r F$ & مرد & \multirow{2}{*}{$\Delta q-r}$. \\
\hline . rSQV &.$- / . \mu_{K}$ & . / $94 T$ & $-\cdot / \cdot \Delta V$ & 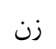 & \\
\hline$\cdot 109$ &.$- \cdot 1 \cdot 1 \mu$ & .1 .49 & $\cdot / \cdot \Delta \kappa^{q}$ & 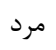 & \multirow{2}{*}{ • •و بيشتر } \\
\hline - MAT & 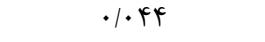 & - KTS & $-.1 .9 V$ & زن & \\
\hline$\cdot / \mathrm{VNI}$ & $-.1 . \vee 4$ & $\cdot / \mathrm{A} \cdot \mathrm{T}$ &.$- / \cdot r \Delta$ & 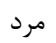 & \multirow{2}{*}{ جمعيت كل } \\
\hline . $/ T A F$ & $.1 . r \varepsilon$ & ( & $-\cdot|| r \mid$ & زن & \\
\hline
\end{tabular}

مردان در تصميم كيرى جهت از بين بردن خود از قاطعيت

و جديت بسيار بالايى برخوردار بوده و براى پايان دادن به زندگى خود از روشهايى با ميزان كشندگى بالا استفاده مى كنند و همجزنين مردان بيشتر با مشكلات اقتصادى و اجتماعى كه منجر به خودكشى مىشود مواجه مى مردند

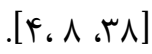

با توجه به مطالعه حاضر 94/1 درصد از اقدام به خودكشىها در زنان رخ داده بود، همرجنين نتايج مطالعه دorgi برزيل و مطالعه Khorshidi در استان ايلام فراوانى اقدام به خودكشى در بين زنان بيش از مردان بيان شده بود، نتايج مطالعات ذكر شده نشان دهنده اين است كه زنان در مقايسه با مردان و به دلايل عديدهاى نظير مسائل فرهنكى، روانى و جسمى در معرض خطر بيشترى از اقدام به خودكشى قرار

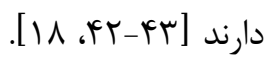
با توجه به نتايج يزوهش حاضر براساس محل سكونت، فراوانى موارد اقدام به خودكشى در ساكنين مناطق شهرى بيشتر از مناطق روستايى بوده كه برخلاف يزوهش حاضر

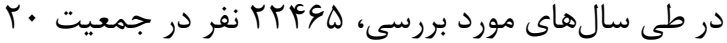
شهرستان تحت يوشش دانشكاه علوم يزشكى مازندران خودكشى كرده بودند كه از اين تعداد درصد) خودكشى آنها به مرك منجر شده بود. در مطالعه حاضر، •9 درصد از افرادى كه خودكشى كامل كرده بودند مرد بودند كه نتايج اين مطالعه همانند اكثر يزوهشهاى انجام شده در داخل و خارج كشور همجون Mobaraki Hajebi سطح ايالت كنتاكى آمريكا و همجنين مطالعه Ngui دركشور كانادا همسو بوده است كه ميزان مرگ ناشى از خودكشى، درجنس مردان بيشتر از جنس زنان كزارش شده بود

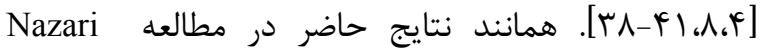
Kangavari خودكشى كامل در استانهاى ايلام، لرستان، كرمانشاه و

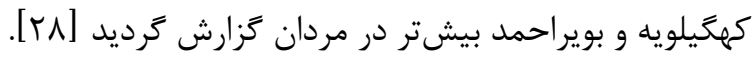


به خودكشى استفاده از داروهاى اعصاب و روان عهاهـ درصد نسبت به ساير روشها، بيشتر استفاده شده بود. در شمال كشور نسبت به ساير استانها قرص برنج به فراوانى يافت مىشود كه يكى از روشهاى متداول خودكشى در شمال مىباشد. برخلاف يزوهش حاضر، نتايج مطالعه Ngui در كانادا روش خودكشى در مناطق روستايى از سلاح گرم و در مناطق شهرى مسموميت و حلقآويز كردن و نتايج مطالعه Cheung در استراليا مسموميت با آفتكشها در

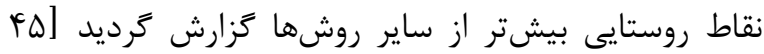
[F]。 برخلاف يزوهش حاضر، مطالعه Hajebi بيشترين روش

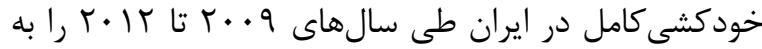
دارآويحتن و مصرف بيش از حد دارو عنوان كرد [ی؟]. با توجه به يافتههاى Azizpour و همكارانش شهرستانهاى ايلام، سيروان وجرداول، ايوان، بدره و دره شهر در استان ايلام بيشترين خودكشى (كامل، اقدام) گزارش شده بود و افرادى كه در اين مدت · r ساله خودكشى (كامل، اقدام) كرده بودند از روش خودسوزى بيشتر استفاده شده بود [19]. با توجه به نتايج مطالعه Nazari Kangavari و همكارانش، زَزارش خودكشى كامل در استان كرمانشاه بيشتر از استانهاى ايلام، لرستان و كهگيلويه و بويراحمد بود و همرجنين در استان كرمانشاه روشهاى حلق آويز، خودسوزى و مسمويت در خودكشى كامل بيشتر از ب استان

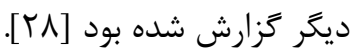
با توجه به نتايج مطالعه Moghaddamnia و همكارانش، در غرب مازندران (رامسر و تنكابن) در طى سالهاى IIV
نتايج مطالعه Ngui در كانادا، نتايج مطالعه Rossen در سطح شهرستانهاى ايالت متحده آمريكا و مطالعه Cheung در استراليا Mirahmadizadeh در استان فارس فراوانى خودكشى در مناطق روستايى را بيشتر ززارش كرده بودند

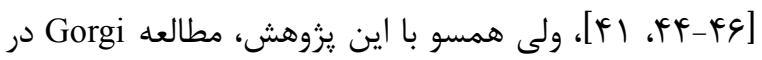
استان فارس وFaria از برزيل ميزان خودكشى در مناطق را

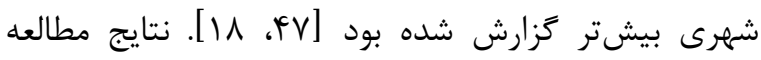
Tomita مقايسه نتايج مطالعه حاصل از تجزيه و تحليل زمانى و مكانى خودكشى و تفكيك دورههاى زمانى در طى سالهاى مختلف، ميزان خودكشى مردان و زنان در حاشيه شهرهاى بزرى افزايش زيادى داشت [^^]. فراوانى خودكشى در مازندران شايد به ويزگى هاى خاص و بافت روستايى و فاصله نزديك بين شهر و روستا و كم شدن تفاوت بين روستايى بودن و شهرى بودن از نظر امكانات و فرهنكى نبايد فراموش شود ولى به هر حال خودكشى در جمعيت روستايى در آمارهاى جهانى همواره كمتر از جمعيت شهرى است. يس وقوع خودكشى بيشتر در جمعيت روستايى قابل توجه است، زيرا استرسهاى ويزهاى كه با زندگى شهرى تعريف شدهاند در روستا كمتر ديده مى -

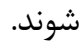
براى انجام خودكشى روشهاى متفاوتى وجود دارد كه با توجه به در دسترس بودن و استفاده آسان از آن در بين اقوام و جوامع مختلف جهان مورد استفاده قرار مى گيرد [^ז،هأ، [F]] با توجه به نتايج اين يروهش رايجترين روش در انجام خودكشى كامل مصرف قرص برنج ا أ درصد و در اقدام 
اييدميولوزى جغر افيايى خود كثى (كامل و اقدام) در شهرستانهاى .... .

از محدوديتهاى اين مطالعه، به دليل انخَ اجتماعى ناشى

از خودكشى، امكان كردآورى اطلاعات از برخى اقدامكنندكان به خودكشى و نيز برخى مسائل از جمله علت انجام خودكشى وجود نداشت كه اين موضوع به دليل لزوم رعايت موازين اخلاقى اجتنابٍيذير بود. انجام مطالعات بيشتر در زمينه علل و انگَيزه افراد جهت خودكشى در مناطق با خطر بالاى خودكشى در شهرهاى ير جمعيت استان ييشنهاد مى-

\section{نتيجه}

با توجه به الكوى جغرافياى، كزارش خودكشى (كامل و اقدام) در اكثر گروه هاى سنى و جنسى در شهرهاى يرجمعيت بيشتر مشاهده شده بود. استفاده از روش مصرف قرص برنج در خودكشى كامل و روشهاى خشن و كشنده در برخى از مناطق استان بالا بود. بنابراين لازم است توجه خاصى در فروش و نكَدارى قرص برنج در استان به عمل

\section{تشكر و قدردانى}

به اين وسيله برخود لازم مى دانم مراتب تشكر صميمانه خود را از اساتيد و مسئولان يزوهشى دانشعاه علوم يزشكى رفسنجان كه ما را در انجام و ارتقاء كيفى اين يزوهش يارى دادند و حمايت مالى لازم را در انجام اين يزوهش داشتند، اعلام نماييم. از مديران و كارشناسان واحد بهداشتروان شبكههاى بهداشتى و درمانى و كارشناسان حراست دانشكاه علوم يزشكى مازندران كه در جمعآورى اطلاعات، نويسندگان اين مقاله را مساعدت و همكارى

$$
\text { لازم نمودند تشكر و قدردانى داريم. }
$$

rrVIا، مسموميت با دارو و سموم كشاورزى بيشترين روش اقدام به خودكشى بود كه در مردان بيشتر از زنان رخ داده بود [•0]، و همرجنين با توجه به نتايج مطالعه Gorgi و همكارانش، بيشترين روش خودكشى كامل در استان فارس حلقآويز و خودسوزى گزارش شده بود كه از شهرستانهاى شيراز، ممسنى، فيروزآباد، لارستان و فراشبند كَارش شده بود. الكَى جغرافيايى خودكشى در استان مذكور نشان داد كه بيشترين ميزان حلق آويز در شهرهاى فيروزآباد، فراشبند و لارستان ززارش شده بود و بيشترين ميزان خودسوزى در شهرهاى ممسنى، شيراز و فيروزآباد گزارش شده بود [^]. با توجه به نتايج مطالعه حاضر ميزان خودكشى(كامل و اقدام)، مقدار شاخص Moran’s I در جنس مردان (V|V|• نشان مىدهد ولى در جنس زنان شاخص Moran’s I جون مقدار شاخص بالاتر از صفر (r•|•) مىباشد، همبستگى مكانى ضعيفى بين مناطق را نشان مىدهد و برخلاف يزوهش حاضر نتايج مطالعهاى كه در سال 11 • ب در برزيل و اكوادور انجام شده بود كه در تحليل همبستگى مكانى كليه متغيرهاى جامع شناختى مقادير، شاخص Moran را بالاتر از ه/• داشتند كه همبستخى مكانى متوسط تا قوى را نشان مىدهد [UY-QY]. با توجه به نتايج مطالعه Gorgi و همكارانش هيج مدركى در مورد همبستكى مكانى (يعنى مناطق مجاور يكديگر تمايل به نرخ خودكشى مشابهى) بين سه روش متداول خودكشى (مصرف بيش از حد مواد مخدر،

خودسوزى، حلقآويز) وجود ندارند [^]. 


\section{References}

[1] Amos T, Appleby L. Suicide and deliberate self-harm. Appleby, DM Forshaw, T. Amos, H. Barker, Postgraduate psychiatry: Clinical and scientific foundations 2001; 347-57.

[2] Rozanov V. Stress and Epigenetics in Suicide, New York, Springer 2017; 236.

3] Dantas AP, Azevedo UN, Nunes AD, Amador AE, Marques MV, Barbosa IR. Analysis of suicide mortality in Brazil: spatial distribution and socioeconomic context. Bras_psiquiatr 2018; 40(1): $12-8$

[4] Mobaraki K, Ahmadzadeh J. The comparison trend of suicide in Hamadan province in 2006 to 2010: a death registry system-based study. J Mazandaran Univ Med Sci 2019; 30(1): 41-8.

[5] Colombo-Souza P, Tranchitella FB, Ribeiro AP, Juliano Y, Novo NF. Suicide mortality in the city of São Paulo: epidemiological characteristics and their social factors in a temporal trend between 2000 and 2017. Retrospective study. Sao Paulo Med J 2020.

[6] Wang Z, Yu G, Tian X. Exploring behavior of people with suicidal ideation in a Chinese online suicidal community. Inte j Envir Res Public Health 2019; 16(1): 54

[7] Rezaeian M, Dunn G, Leger S, Appleby L. Geographical epidemiology, spatial analysis and geographical information systems: a multidisciplinary Glossary. J Epidemiol Community Health 2007; 61:98-102.

[8] Gorgi Z, Sheikh FM, Vazirinejad R, Rezaelan M. Geographical epidemiology of suicide and suicide attempts during the years 2010-2013 in Fars Province, Iran.

[9] Hempstead K. The geography of self-injury: Spatial patterns in attempted and completed suicide. Social Science \& Medicine 2006; 62: 3186-96.

[10] World Health Organization. Mental health suicide prevention 2017. Availablefrom: http: ewww.WHO.int/mental_health/prevention/suicide/sui cideprvent/en. (lastaccesedNov2019).

[11] Bachmann S. Epidemiology of suicide and the psychiatric perspective Inte $j$ envir res public health 2018; 15(7): 1425 
[12] Pitman A, De Souza T, Khrisna Putri A, Stevenson F, King M, Osborn D, et al. Support needs and experiences of people bereaved by suicide: qualitative findings from a cross-sectional British study of bereaved young adults. Inte J Envir Res Public Health 2018; 15(4): 666.

[13] Bailey E, Alvarez-Jimenez M, Robinson J, D’Alfonso S, Nedeljkovic M, Davey CG, et al. An enhanced social networking intervention for young people with active suicidal ideation: Safety, feasibility and acceptability outcomes Inte J Envir Res Public Health 2020; 17(7): 2435.

[14] Armstrong G, Vijayakumar L, Niederkrotenthaler T, Jayaseelan M, Kannan R, Pirkis J, et al. Assessing the quality of media reporting of suicide news in India against World Health Organization guidelines: A content analysis study of nine major newspapers in Tamil Nadu 2018. Australian \& New Zealand Journal of Psychiatry 2018; 52(9): 856-63.

[15] Chen YY,Chien Chang Wu K, Yousuf S,Yip PS. Suicide in Asia. Opportunities and challenges. Epidemiologic reviews 2012; 34(1): 129-44.

[16] Hoven CW, Mandell DJ, Bertolote JM. Prevention of mental ill-health and suicide: Public health perspectives. European Psychiatry 2010; 25(5): 252-

6.

[17] Rafiee M, Seifi A. Epidemiological study of suicide attempters referred to hospitals affiliated to Markazi University of Medical Sciences since 2005 to 2007. SID 2008, 4(3): 59-69.

[18] Gorgi Z, Sheikh Fathollahi M, Vazirinejad R, Rezaeian M. A comprehensive spatial epidemiology of suicide and suicide attempts in Fars Province. $J$ Sui Prevention 2019; 1(1): 14-23.

[19] https://fa.wikipedia.org/w/index.php.title. Suicide in Iran.

[20] Karamouzian M, Rostami M. Suicide statistics in Iran: let's get specific American j Men's Health 2019; 13(1).

[21] Rostami M, Jalilian A, Rezaeian S, Kamali A. Gender and Spatial Disparities of Suicide Mortality Risk in Kermanshah Province, Iran: A Brief Report. Dsahm J 2019; 1(3): 55-7.

[22] Taziki MH, Semnani S, Shahriyar, Gol Alipour M J, Behnampour N, Taziki SA, Rajaei S, et al. Epidemiology of suicide in Golestan province 2003. Mazandaran University of Medical Sciences 2006; 16 (55): 72-7. [Farsi] 
[23] Haghparast-Bidgoli H, Rinaldi G, Shahnavazi H, Bouraghi H, Kiadaliri A. Socio-demographic and economics factors associated with suicide mortality in Iran 2001-2010: application of a decomposition model. International Journal for Equity in Health 2018; $17: 77$.

[24] Lee H-C, Lin H-C, Tsai S-Y, Li C-Y, Chen C-C, Huang C-C. Suicide rates and the association with climate: A population-based study. Journal of Affective Disorders 2006; 92: 221-6.

[25] Daliri S, Bazyar J, Sayehmiri K, Delpisheh A, Sayehmiri F. The incidence rates of suicide attempts and successful suicides in seven climatic conditions in Iran from 2001 to 2014: a systematic review and meta-analysis. Sjku 2016; 21: 1-15. [Farsi]

[26] Azizpour Y, Asadollahi K, Sayehmiri K, Kaikhavani S, Abangah G. Epidemiological survey of intentional poisoning suicide during 1993-2013 in Ilam Province, Iran. BMC Public Health 2016; 16(1): 1-2.

[27] Nazarzadeh M, Bidel Z, Ranjbaran M, Hemmati R, Pejhan A, Asadollahi K, et al. Fatal Suicide and Modelling its Risk Factors in a Prevalent Area of Iran. Archives of Iranian Medicine 2016; 19(8): 5716.

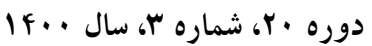

[28] Nazari Kangavari H, Shojaei A, Nazari SS. Suicide mortality trends in four provinces of Iran with the highest mortality, from 2006-2016. SID 2017; 17(2): 382.

[29] Soltani S, Aghakhani K, Barzegar A, Ghadirzadeharani M, Fallah F. Epidemiology of Completed Suicides Referred to Forensic Pathology Organization of Tehran, Iran, During March 2011 to March 2016. Inte J Med Toxi Forensic Med 2017; 7(3): 151-8.

[30] Shakeri A, Jafarizadeh F. The reasons for successful suicides in Fars province. J Mazandaran Univ Med Sci 2013; 22(97): 271- 5. [Farsi]

[31] Ahmadi M, Ranjbaran H, Azadbakht M, Gorji MH, Gorji AH. A survey of characteristics of selfimmolation in the northern Iran. Annals of medical and Health Sciences Research 2014; 4(3): 228-32.

[32] Jafari F, Ahmadi A, Moosazadeh M. Seasonality pattern of suicide in Iran: A systematic review. Journal of School of Public Health and Institute of Public Health Research 2015; 12(3): 23-35. [Farsi].

[33] Ahmadi A.M, Haji Ahmadi M. Report epidemiology of suicide in mazandaran province in yeears1992-1993. J Mazandaran Univ Med Sci 2001: 28. [Farsi] 
[34] Zarenezhad M, Gorgi Z, Sheikh Fathollahi M, Gholamzadeh S, Ghadipasha M, Rezaeian M. Epidemiological Survey of Suicide in Fars Province in the south of Iran during 2003 to 2011. JOHE 2015; 13(12): 1129-40. [Farsi]

[35] Bantjes J, Tomlinson M, Weiss RE, Yen PK, Goldstone D, Stewart J, et al. Non-fatal suicidal behaviour, depression and poverty among young men living in low-resource communities in South Africa. BMC Public Health 2018; 18(1): 1195.

[36] www.mazums.ac.ir.

[37] www.mporg.ir/filesystem/view/file.aspx.filed. 3b17806f- e323-4224-9358-453df38cd712.

[38] Hajebi A, Ahmadzad-Asl M, Davoudi F, Ghayyomi R. Trend of suicide in Iran during 2009 to 2012: Epidemiological evidences from national suicide registration. Iran J Psychiatry Behav Sci 2016; 10(4).

[39] Santos EG, Oliveira YO, Azevedo UN, Nunes AD, Amador AE, Barbosa IR. Spatial temporal analysis of mortality by suicide among the elderly in Brazil. Revista Brasileira de Geriatria e Gerontologia 2017; 20(6): 845-55.

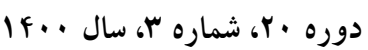

[40] Saman DM, Walsh S, Borówko A. Does place of residence affect risk of suicide? A spatial epidemiologic investigation in Kentucky from 1999 to 2008. BMC Public Health 2012; 12(1): 108.

[41] Ngui AN, Apparicio P, Moltchanova E, Vasiliadis HM. Spatial analysis of suicide mortality in Québec: spatial clustering and area factor correlates. Psychiatry Research 2014; 220(1-2): 20-30.

[42] Boas AC, Monteiro QR, Silva RP, Meneguetti DU. Profile of suicide attempts treated in a Public Hospital of Rio Branco, Acre State from 2007 to 2016. J Hum Grow Dev 2019; 29(1): 57-64.

[43] Khorshidi A, Sayehmiri K, Babanejad M. Seasonality of suicide occurrence in Ilam. SID 2014; 9(3): 17-23.

[44] Rossen LM, Hedegaard H, Khan D, Warner M. County-level trends in suicide rates in the US, 20052015. American J of Preven Med 2018; 55(1): 72-9.

[45] Cheung YT, Spittal MJ, Pirkis J, Yip PS. Spatial analysis of suicide mortality in Australia: investigation of metropolitan-rural-remote differentials of suicide risk across states/territories. Social Science \& Medicine 2012; 75(8): 1460-8. 
[46] Mirahmadizadeh A, Rezaei F, Mokhtari AM, Gholamzadeh S, Baseri A. Epidemiology of suicide attempts and deaths: a populationbased study in Fars, Iran 2011-16. J Public Health 2019; 42(1): 1-11.

[47] Faria G, de Carvalho AA, Romanha LM, Lima AC. Epidemiological Study of Suicide Cases between Youth and Adults from 2010 to 2018 in Cacoal City, Rondonia, Brazil. Inte J Adv Eng Res Science 2019; $6(10)$.

[48] Tomita M, Kubota T, Ishioka F. Spatial Clustering Properties in the Temporal Variation of Suicide Rates/Numbers among Japanese Citizens: Comprehensive Comparison and Discussion 2015; 10(7).

[49] Azizpour Y, Asadollahi K, Sayehmiri K, Kaikhavani S. Investigation of the outcomes and varieties of violent suicides during a period of twenty years in Ilam, Iran 2016; 75(7): 530-7. [Farsi]

[50] Moghaddamnia A. Suruey of acute suicidal poisoning in the west of Mazandaran prouince during the years 1994-1996. J Mazandaran Univ Med Sci 1999; 9(22): 18-25. [Farsi]

[51] Dantas A, de Azevedo U, Nunes A, Amador A, Marques M, Barbosa I. Analysis of suicide mortality in Brazil: spatial distribution and socioeconomic context. Revista Brasileira de Psiquiatria 2018; 40: $12-8$.

[52] González S, Vinueza A, Gault C, DelgadoRon A. Trends and Spatial Patterns of Suicide Among Adolescent in Ecuador, 1997-2016. Clinical Practice \& Epidemiology in Mental Health 2018; 14. 
..... إيبدميولوزى جغرافيايى خود كشى (كامل و اقدام) در شهرستانهاى TV

\title{
Geographical Epidemiology of Suicide (Completed and Attempted) in the Townships Covered by Mazandaran University of Medical Sciences during the Years 2012 to 2016: An Ecological Study
}

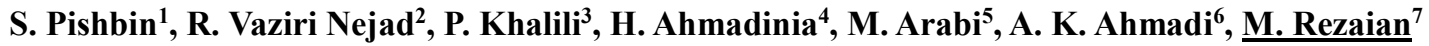 \\ Received:20/12/20 Sent for Revision: 04/01/21 Received Revised Manuscript:14/03/21 Accepted: 15/03/21
}

Background and Objectives: Suicide is one of the biggest medical and social problems in the world. The aim of this study was to investigate the geographical epidemiology of suicide (completed- attempted) in the townships covered by Mazandaran University of Medical Sciences during the years 2012 - 2016.

Materials and Methods: In this ecological study, information was collected using the checklist of the monthly report of the suicide prevention program in the hospitals of Mazandaran University of Medical Sciences. Spatial correlation of suicide age-sex groups was calculated using Moran's index (I). Data were analyzed using descriptive statistics and Chisquare test.

Results: 376 cases (1.67\%) had completed suicides and 22089 cases $(98.33 \%)$ had suicide attempts. Of the total number of people who committed suicide, 68.5\% (15389 cases) were urban and 31.5\% (7076 cases) were rural. The highest number of suicide attempts was reported from Amol city 3549 cases (16.07\%) and the highest number of completed suicides was reported from Sari city 65 cases (17.29\%). In cases of completed suicide, the most common method of suicide in Sari and Amol counties was the use of rice pills and in the cities of Gulogah and Nowshahr was hanging. In cases of suicide attempts, the use of psychiatric drugs was the most reported in Ghaemshahr and Amol counties.

Conclusion: According to the geographical pattern, the number of suicides (completeed and attempted) was higher in most age and sex groups in densely populated cities. The use of rice pill consumption method in completed suicide and violent and lethal methods was high in some areas of the province.

Key words: Completed suicide, Attempt, Epidemiology, Mazandaran, Geographical

Funding: This study was funded by Research Committee of Rafsanjan University of Medical Sciences.

Conflict of interest: None declared.

Ethical approval: The Ethics Committee of Rafsanjan University of Medical Sciences approved the study (IR.RUMS.REC.1397.064).

How to cite this article: Pishbin S, Vaziri Nejad R, Khalili Kh, Ahmadinia H, Arabi M, Ahmadi A K, Rezaian M. Geographical Epidemiology of Suicide (Completed and Attempted) in the Townships Covered by Mazandaran University of Medical Sciences During the Years 2012 to 2016: An Ecological Study. J Rafsanjan Univ Med Sci 2021; 20 (3): 259-76. [Farsi]

1- MSc Student of Epidemiology, Rafsanjan University of Medical Sciences, Rafsanjan, Iran, ORCID: 0000-0003-4969-0690

2- Prof., Dept. of Community Medicine, Occupational Environmental Research Center, Medical School, Rafsanjan University of Medical Sciences, Rafsanjan, Iran, ORCID: 0000-0002-1967-7631

3- PhD Student of Epidemiology, Dept. of Epidemiology and Biostatics, Occupational Environmental Research Center, Medical School, Rafsanjan University of Medical Sciences, Rafsanjan, Iran, ORCID: 0000-0002-0486-934X

4 PhD Student of Biostatistics, Dept., of Biostatistics, School of Public Health, Hamadan University of Medical Sciences, Hamadan, Iran, ORCID: 0000-0002-7010-1726

5- MD, Assistant Prof., Mazandaran University of Medical Sciences, ORCID: 0000-0003-3811-8306

6- Psychiatrist, Head of the Department of Mental Health Addiction, Mazandaran University of Medical Sciences, ORCID: 0000-0001-71863127

7- Prof., Dept. ofCommunity Medicine, Occupational Environmental Research Center, School of Medicine, Rafsanjan University of Medical Sciences, Rafsanjan, Iran, ORCID: 0000-0003-3070-0166.

(Corresponding Author) Tel: (034) 34264003, Fax: (034) 34255209, E-mail: moeygmr2@yahoo.co.uk

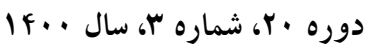

مجله دانشگاه علوم يزشكى رفسنجان 